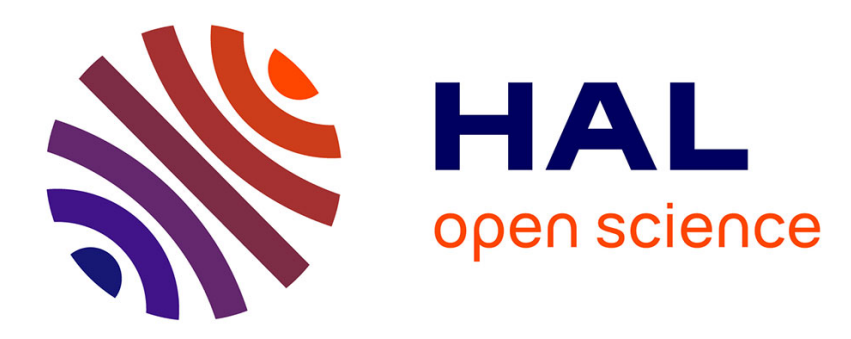

\title{
STUDY ON THE MULTILAYER EXPLOSIVE CLADING OF THIN AMORPHOUS FOILS
}

\author{
K. Zhang, Xiaojian Li
}

\section{To cite this version:}

K. Zhang, Xiaojian Li. STUDY ON THE MULTILAYER EXPLOSIVE CLADING OF THIN AMORPHOUS FOILS. Journal de Physique IV Proceedings, 1991, 01 (C3), pp.C3-229-C3-234. 10.1051/jp4:1991331 . jpa-00250473

\section{HAL Id: jpa-00250473 https://hal.science/jpa-00250473}

Submitted on 1 Jan 1991

HAL is a multi-disciplinary open access archive for the deposit and dissemination of scientific research documents, whether they are published or not. The documents may come from teaching and research institutions in France or abroad, or from public or private research centers.
L'archive ouverte pluridisciplinaire HAL, est destinée au dépôt et à la diffusion de documents scientifiques de niveau recherche, publiés ou non, émanant des établissements d'enseignement et de recherche français ou étrangers, des laboratoires publics ou privés. 


\title{
STUDY ON THE MULTILAYER EXPLOSIVE CLADING OF THIN AMORPHOUS FOILS*
}

\author{
K. ZHANG and $\mathrm{X}$. LI \\ Institute of Engineering Mechanics, Dalian University of \\ Technology, Dalian, P.R. China
}

\section{RESUME :}

Un cylindre de $2 \mathrm{~cm}$ de diamètre extérieur, $4 \mathrm{~mm}$ d'épaisseur et $8 \mathrm{~cm}$ de longueur, constitué de 165 feuilles d'un alliage amorphe à base de fer (2605S-2) a été fabriqué par soudage à l'explosif en géométrie axisymétrique multicouches.

On explique le principe du soudage par explosif des feuilles amorphes et on analyse le saut de température de cristallisation associé au soudage par explosif d'un alliage amorphe.

Abstract-The cylinder of 165. layers 2605S-2 amorphous foils having dimensions as large as $2 \mathrm{~cm}$ in outside diameter with $4 \mathrm{mmth}-$ ickness and lengh of $8 \mathrm{~cm}$ by axial-symmetrical multilayer explosive welding has been fabricated. The principle of explosive welding for amorphous foils and crystallization temperature bound of explosive welding of amorphous alloy have been given.

The amorphous materials have many captivating properties.such as high strengh, high hardness, lower magnetic hysteresis loss and excellent anticorrosion. The one of reasons which cann't be gained wide applications is geometric shape of products being restricted, because in order to obtain the rate of cooling $10^{6} \mathrm{k} / \mathrm{s}$, the product manufactured

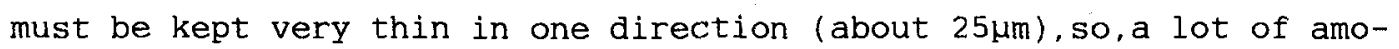
rphous alloy is fashioned in form of pellets, foils, ribbon stock and porder shape. For amorphous iron-base Metglas.it possesses low coercive force,high magnetic conductivity, the resistivity is about three times of silicoferrite,but the core loss is only one forth of it. However the cause of restricting the application to electromagnetic en-

* This subject is supported by NAMCC. 
gineering is that the ribbon is too thin and rendered the packing density lower, only about $75 \%$ to $80 \%$. Therefore, there are urgent reqirements to fashion larger three-dimension bulk of amorphous materials. Murr et al /1,2/ had reported the explosive consolidation of amorphous iron-base 2605s-2 Metglas powder to fabricate succefully cylinder having dimensions as large as $2.5 \mathrm{~cm}$ in outside diameter with $7 \mathrm{~mm}$ wall thickness and lengths of more than $5 \mathrm{~cm}$ and concluded that the magnetic properties of the initial porder particles were not degraded in any significant way as a result of the explosive processing, and the amorphous structure is still perpetuated. In this paper we have fabricated the cylinder of 165 layers 2605S-2 amorphous foils having dimensions as large as $2 \mathrm{~cm}$ in outside diameter with $4 \mathrm{~mm}$ thickness and length of $8 \mathrm{~cm}$ by axial-symmetrical multilayer explosive welding.

1. -Experiments.

The experimental assembly is shown in fig 1 . Winding the amorphous $f-$ oils into a scroll, taking advantage of the crudeness of ground surface having micrometer measurements, there are natural stand of $f$ between two layers, this stand-off is just the measure of ribbon thickness. Inside vacuumized, the explosive is detonationed from top, the velocity of explosive is $4170 \mathrm{~m} / \mathrm{s}$, the theoretical solid density is $p=7.3 \mathrm{~g} / \mathrm{cm}^{3}$ and the green packing density of amorphous ribbon is $\rho_{0}=4.447 \mathrm{~g} / \mathrm{cm}^{3}$. Some measurements for recovery sample indicated that the compaction density is $98 \%$ of T.D. . Through metallographic examination its shown well for welding quality. The retention and perpetuation of amorphism was also supported by X-ray diffraction studies. The samples obtained by explosive welding is shown in fig 2 . 


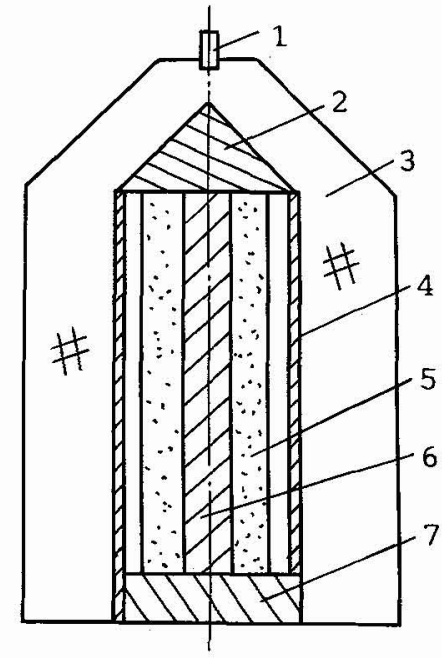

Fig1. The set-up for explosion 1-detonator, 2-plug, 3-explosive. 4-flyer tube, 5-ribbon,6-core,

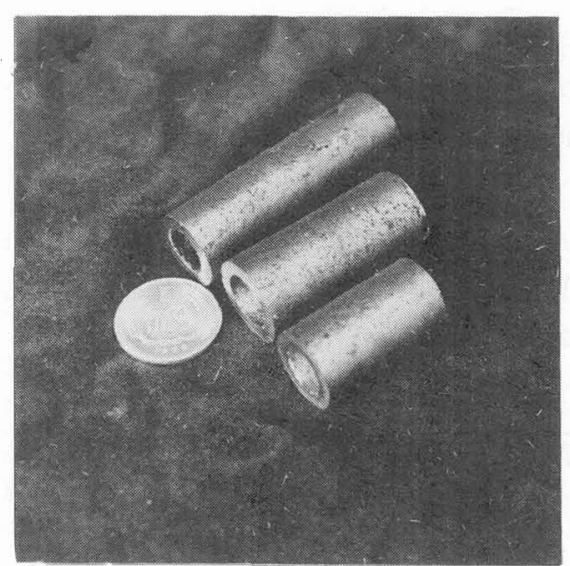

Fig2. The samples fashioned. by explosive welding

2. The principle of explosive welding for amorphous foils.

In order to weld the amorphous foils together, the following conditions must be satisfied:

(1) The impacted velocity between layers must be achieved certain minimum /3/. For thin foils, the formula of lower limit of explosive welding $u_{p}=k / H_{v} / \rho$ is also used, in which $u_{p}$ is impacted velocity between layers,k-coefficient.

(2) Owing to the ribbon foils is too thin, after impact, the bending $w-$ ave will be occured in it. If the velocity of impacted point is smaller than a certain prescribed minimum $\mathrm{c}_{\mathrm{g}}$, the bending waves will appear in the front of impacted point of ribbon foils and result to failure of welding. This velocity $\mathrm{c}_{\mathrm{g}}$ approximately equals to a half velocity of elastic longitudinal wave or the velocity of transmission of shear wave /4/.

(3) In the welding of amorphous alloy, the shearing fracture will be produced $/ 5,6 /$. In order to prevent the shearing fracture we have proposed 20 times specific strength for strength limit,i.e. $\frac{1}{2} \rho v_{c}{ }^{2} \geq 20 \sigma_{b}$, where $v_{c}$-the velocity of impacted point, $\sigma_{b}$-static tensile strength. For 2605S-2 amorphous foils, the velocity of impacted point calculated by the condition of avoiding shearing fracture was mostly greater than that value $\mathrm{c}_{\mathrm{g}}$ of occuring bending wave. 
(4) In the welding of amorphous alloy, the impacked energy must be smaller than certain value and make the terminal temperature smaller than the crystallization temperature, $u_{p}{ }^{2}<2 c_{p}\left(T_{x}-T_{0}\right)$, where $u_{p}$ is impacted velocity between layers of amorphous foils, $c_{p}$ is specific heat of amorphous materials at constant pressure, $t_{x}$-crystallization temperature, $\mathrm{T}_{0}$-room temperature.

3.-The crystallization temperature bound of explosive welding of amorphous alloy.

According to the characteristic $\mathrm{T}-\mathrm{T}-\mathrm{T}$ of crystal growth in overing $\mathrm{m}-$ elt (shown in fig 3) /7/, when melt is cooling quickly from melt point $T_{m}$ to $T_{n}$ in the time which is shorter than the shortest time $t_{\text {min }}$ required for crystallization, the retention of overcooling melt will be occured, then at the transformation temperature of glass $T_{g}$,itś configuration is congealed to form glass. If the glass is heated to certain temperature $\mathrm{T}$ which is below $\mathrm{T}_{\mathrm{n}}$ and keep this temperature constant in some $t_{x}$, it will begin to crystallize.

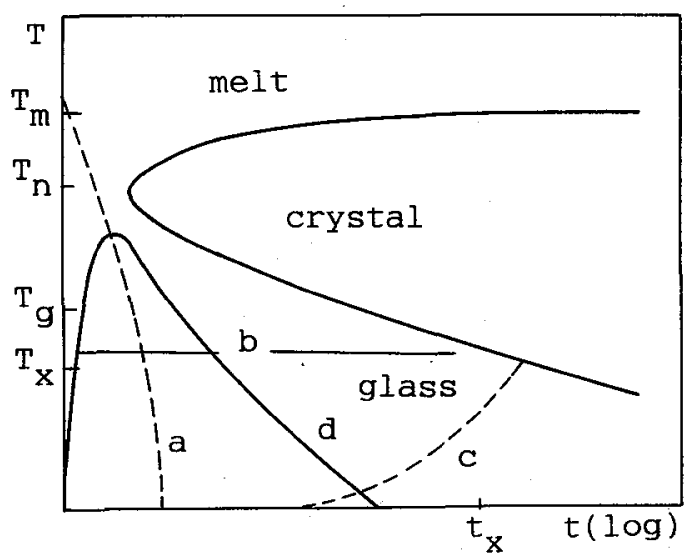

Fig3. The characteristic T-T$T$ of crystal glowth in overcooling melt

a-cooling quickly to form glass. b-the glass is heated isothermally and begin to crystallize at time $t_{x}$. c-heating slowly and begiin to crystallize at temperature $T_{x}$. dthe amorphism is perpetuated in explosive welding.

on the basis of aforementioned theory, in the explosive welding of amorphous ribbon the ascending and descending velocities of temperature of ribbon must be high enough to ensure not to intersect projecting end of T-T-T curve, then crystallization is prevented.

We proposed two hypothesises for exprosive welding process of amorphous ribbon:

(1) Due to that the impacted welding process is accomplished in $10^{-9}$ $s$ measurements, so we consider that the materials in the vicinity of 
welding interface smelt instantaneously,but keep constant temperature inside the ribbon.

(2) the energy absorbed by heated-up layer is about $u_{p}^{2} / 2$, but the meit point is determined by simon equation.

(3) The impacted time difference of each layer have not influence on the heat-conduction.

In terms of aforementioned hypothesises, we can simplify the heat conduction question into one dimension model which has adiabatic boundaries in two side, where $\eta$ is melt ratio, $\mathrm{T}_{\mathrm{m}}$-melt point at this moment which is determined by simon melt equation:

$$
T_{m}=T_{m 0}[1+p / a]^{b}
$$

Where $\mathrm{a}=15 \mathrm{Gpa}, \mathrm{b}=1 / 3.2, \mathrm{~T}_{\mathrm{mo}}=1419^{\circ} \mathrm{K}$ melt point at atmosphere. Owing to that the amorphous alloy hasnt latent heat,from above equation and hypothesises (2) we can solve the melt ratio $n$ :

$$
\eta=u_{p}^{2} /\left[2 c_{p}\left(T_{m}-T_{0}\right)\right]
$$

Where $c_{p}$-average heat capacity. $T_{0}$-room temperature, so the heat conduction process of multilayer explosive welding may be depicted by equations listed below:

$$
\begin{aligned}
& \partial T(x, t) / \partial t=\alpha \partial^{2} T(x, t) / \partial x^{2} \\
& \partial T /\left.\partial x\right|_{x=0}=0 ; \quad \partial T /\left.\partial x\right|_{x=h / 2}=0 ; \\
& T= \begin{cases}T_{m} & \eta \cdot H / 2 \geq x \geq 0 \\
T_{0} & H / 2 \geq x \geq \eta \cdot H / 2\end{cases}
\end{aligned}
$$

Where $\alpha$ is heat conductivity coefficient, H-thickness of one layer amorphous foil. Using the method of separating variable to solve above equation:

$$
\begin{gathered}
T=u_{p}^{2} / 2 c_{p}+T_{0}+u_{p}^{2} / 2 \eta c_{p} \sum_{n=1}^{\infty} \sin (n \pi \eta) / 2 n \pi \cos (2 n \pi x / H) \\
. e^{-4(n \pi / H)^{2}} \\
\partial T / \partial t=-u_{p}{ }^{2} / 2 \eta c_{p} \sum_{n=1}^{\infty} 2 \alpha n \pi / H^{2} \sin (n \pi \eta) \cos (2 n \pi x / H) \cdot e^{-4(n \pi / H)^{2} \alpha t}
\end{gathered}
$$

above equations are just the temperature distribution field and the field of rate of temperature change in welding,using both temperature field and T-T-T curve (fig 2 ), we may ascertajn analytically where ha- 
ve the amorphism transformed or not in explosive process. But the forementioned equations are too complicated, however after to analyze equation (4), it can be shown that when the thickness of amorphous ribbon is thiner, at the shortest crystallization time $t_{\text {min' }}$ the term $e^{-4(n \pi / H) \alpha t_{\text {min }}}$ generally is very small. From reference $/ 7 / \mathrm{T}_{\mathrm{m}}-\mathrm{T}_{\mathrm{n}}$ is $10^{2} \mathrm{~K}$, the descending rate of temperature to form glassification $Q^{\text {म }}$ is about $10^{5 \sim 6} \mathrm{~K} / \mathrm{s}$, so $t_{\min }=\left(\mathrm{T}_{\mathrm{m}}-\mathrm{T}_{\mathrm{n}}\right) / \mathrm{Q}^{\mathrm{k}}$ is about $10^{-3} \sim 10^{-4} \mathrm{~s}$, however the heat conductivity of amorphous materials $\alpha$ is about $10^{-6} \mathrm{~m}^{2} / \mathrm{s}$, therefore, for the ribbon of $10 \sim 100_{\mu m}$ thickness we have:

$$
e^{-4 n 2 \pi^{2} / H^{2} \alpha t_{\min }}=e^{-4(1 \sim 10) n} \leq 10^{-2 n}
$$

substituting this into equation (4), we may discover that for the welding of amorphous ribbon of $10 \sim 100 \mu \mathrm{m}$ thickness with time $t_{\text {min }}$, it's already reached constant temperature on the whole. The temperature of whole bulk is:

$$
T=u_{p}^{2} / 2 c_{p}+T_{0}
$$

so that in order to ensure welded sample uncrystallized,its only to ensure the whole temperature rise smaller than general crystallizatiion temperature ' $\mathrm{T}_{\mathrm{X}}$ ' i.e.

$$
\text { or } \begin{aligned}
& u_{p}^{2} / 2 C_{p}+T_{0}<T_{x} \\
& u_{p}^{2}<2 C_{p}\left(T_{x}-T_{0}\right)
\end{aligned}
$$

for $2605 \mathrm{~S}-2$ amorphous ribbon, $\mathrm{T}_{\mathrm{X}}=550{ }^{\circ} \mathrm{C}, \mathrm{T}_{0}=25^{\circ} \mathrm{C}$.

Reference :

/1/ L.E.Murr; et al; Scripta Met. 17:1353 (1983).

/2/ L.E.Murr, Metallurgical Applications of Shock-wave and HighStrain-Rate Phenomena,p329, (1986).

/3/ Shao Bign Hung, Zhang Kai, Principle of Explosive Welding and its Engineering Use, p197, (1987), in chanese

/4/ Zhang Kai, Inter. Conf. on Shock-Wave and High-Strain-Rate Phenomena in Materials; (1990).

/5/ R.Prummer, II Meeting on Explosive Working of Materials, (1981).

/6/ Zhang DengXia, et al, J. Mech. 16(1)(1984), in chanese

/7/ F.E.Luborsky, Amorphous Metallic A.lloy, (1983). 